\title{
Latex-bound antifibrinogen test for plasma fibrinogen assay
}

\author{
D. J. CASTELAN, J. HiRSh, AND M. MARTIN \\ From the University of Melbourne Department of Medicine, St. Vincent's Hospital, Melbourne, \\ Victoria, Australia
}

SYNOPSIS The semiquantitative latex-bound antifibrinogen test (Fi test) can be modified toin quantitate plasma fibrinogen. The test is rapid and simple and does not require complex apparatus. $\overrightarrow{0}$ Although the Fi reagent reacts with early fibrinogen and fibrin breakdown products, the degree of $\mathrm{E}^{\circ}$ interference is not marked and the test is sufficiently accurate to be of clinical value as a fibrinogen ${ }^{\infty}$ assay in patients with increased fibrinolytic activity.

A number of methods are used for the measurement of plasma fibrinogen (Tocantins and Kazal, 1964). These include (1) the estimation of clottable or precipitable protein by gravimetric or colorimetric means; (2) the thrombin clotting time using the time of clot formation as the endpoint (Vermylen, Verstraete, and de Vreker, 1963) or the maximum dilution at which a clot appears as the endpoint (Schneider, 1952); and (3) immunological assays using tanned red cell (Fox, Wide, Killander, and Gemzell, 1965) or a latex-bound antihuman fibrinogen antibody (Fi test).

Assays based on the clottable protein estimation are accurate but time-consuming and thus have diagnostic limitations in acquired haemorrhagic disorders with suspected icute hypofibrinogenaemia. Methods based on the thrombin clotting time are simple and rapid; however, previous investigations have shown that this assay is markedly inhibited by the presence of fibrinogen breakdown products (Hirsh, Fletcher, and Sherry, 1965). An immunological method, the latex-bound antihuman fibrinogen test (Hyland, U.S.A.), has been available as a semiquantitative fibrinogen assay for a number of years, and more recently it has been used as a quantitative assay of plasma fibrinogen (Zucker, Pert, and Hilgartner, 1966). Although fibrinogen breakdown products have been shown to react with the Fi reagent (Hirsh et al, 1965) it is not known to what degree these breakdown products interfere with the quantitative fibrinogen assay. The purpose of this study is to investigate the value of the modified Fi test in the estimation of plasma fibrinogen and to assess the effect of breakdown products of fibrinogen and fibrin on the test.

Received for publication 7 March 1968.

\section{MATERIALS AND METHODS}

Latex particles bound with antihuman fibrinogen ( $F$ reagent) were kindly provided by Hyland, Division of Baxter Laboratories, Australia. It was stable at $4^{\circ} \mathrm{C} . \overrightarrow{\mathrm{G}}$ Human fibrinogen (fraction 1-4 prepared by the methodo or Blombäck and Blombäck, 1956) was kindly supplied by the Commonwealth Serum Laboratories, Victoria, and was found to be $90 \%$ clottable. This preparation of fibrinogen was used to prepare antibodies as previouslyo described (Hirsh et al, 1965). The fibrinogen antiserumb was adsorbed with lyophilized human serum and pro $\mathbb{2}$ duced a single band when reacted by immunodiffusion with human fibrinogen and plasma, but failed to reace with human serum. Plasmin (A. B. Kabi and Co.? Stockholm) was dissolved in distilled water to a con centration of 5 casein units (cu) per $\mathrm{ml}$ and stored. at $-20^{\circ} \mathrm{C}$. Topical thrombin (Parke Davis) dissolvews in $50 \%$ glycerol in $0.9 \% \mathrm{NaCl}$ at a concentration of 1,000 units per $\mathrm{ml}$ was stored at $-20^{\circ} \mathrm{C}$, and diluted.

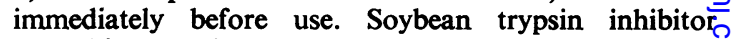
(Worthington Biochem. Co., U.S.A.) was stored at $4^{\circ} \mathrm{C} O$ The serum used to prepare fibrinogen samples was inactivated to eliminate thrombin activity by heating at $56^{\circ} \mathrm{C}$ for 30 minutes.

BREAKDOWN PRODUCTS OF FIBRINOGEN Fibrinogen wa dissolved in $0.1 \mathrm{M}$ borate buffer, $p \mathrm{H} \mathrm{8}$, to a final con centration of $5 \mathrm{mg} / \mathrm{ml}$. Breakdown products werq prepared by inhibiting proteolysis at two hours (earl, breakdown products) and 24 hours (late breakdown products) by the addition of $1 \mathrm{mg}$ of soybean trypsip inhibitor per casein unit of plasmin present in the solution. The inactivation of the plasmin was confirmec by fibrin plate assay.

BREAKDOWN PRODUCTS OF FIBRIN Fibrin breakdown? products were prepared by lysis of a fibrin clot. The clop was prepared by adding 2 units of thrombin to $5 \mathrm{ml}$ oळि a $5 \mathrm{mg} / \mathrm{ml}$ solution of fibrinogen Plasmin was addeof 638 
immediately after clotting and lysis was inhibited at two hours (early fibrin breakdown products) and 24 hours (late fibrin breakdown products) by the addition of soybean trypsin inhibitor. The inactivation of the plasmin was confirmed by fibrin plate assay.

IMMUNOLOGICAL TECHNIQUES Immunoelectrophoresis was performed as described by Crowle (1961) using a micromethod and $1 \%$ agar (Ionagar no. 2, Oxoid Consolidated Laboratories, Inc., Chicago Heights, Ill.) in barbital buffer, $p H \quad 8 \cdot 6$, ionic strength 0.05 . Electrophoretic separation was performed in barbital buffer, $p \mathrm{H} 8 \cdot 6$, ionic strength $0 \cdot 5$, using a Shandon apparatus at $90 \mathrm{~V}$ for $2 \mathrm{hr}$ and voltage control.

PATIENT STUdies Venous blood from patients and controls was collected in siliconized $20 \mathrm{ml}$ syringes and mixed with $3.8 \%$ trisodium citrate in the ratio of 9 parts of blood to 1 part of anticoagulant. The blood was centrifuged at $3,000 \mathrm{~g}$ for 15 minutes and the platelet-poor plasma separated and tested.

\section{ASSAY OF FIBRINOGEN}

The modified Fi test Preliminary attempts were made to quantitate the Fi test using plasma which was serially diluted until agglutination failed to occur. This technique proved unsatisfactory because it was necessary to dilute the plasma to approximately 1 in 10,000 to eliminate agglutination. At these high dilutions the endpoint was difficult to establish because the clumps were small and poorly defined. The assay was therefore performed using the agglutination time rather than the presence of agglutination as the endpoint. A plasma sample of known fibrinogen level was serially diluted in heat-inactivated serum. Each of the samples was further diluted $1 / 200$ and $1 / 1,000$ in borate buffer and standard curves were obtained for both dilutions. From these two standard curves it was possible to establish a range of fibrinogen concentrations from 40 to $400 \mathrm{mg} \%$ (Fig. 1). The $1 / 200$ dilution curve gave more accurate results for low fibrinogen concentrations but fibrinogen concentrations above $200 \mathrm{mg} \%$ could only be adequately quantitated using the $1 / 1,000$ dilution curve.

A $10 \mu \mathrm{l}$ aliquot of Fi reagent was mixed with $10 \mu \mathrm{l}$ of diluted plasma on a glass slide. This was tilted intermittently to facilitate mixing, and the onset of macroscopically visible clumping was recorded. For fibrinogen concentrations in the detectable range (40 to $400 \mathrm{mg} \%$ ) a sharp endpoint appeared between 15 and 35 seconds. This endpoint was most readily detected in daylight against a flat dark background.

Clottable protein method The method of Ratnoff and Menzie (1951) was used as modified by Alkjaersig, Fletcher, and Sherry (1959).

Thrombin time assay of fibrinogen The thrombin time was performed as previously described (Alkjaersig et al, 1959). A standard curve (Fig. 2) was obtained by testing pooled human plasma of known fibrinogen concentration in serial dilutions of heat-inactivated serum. The samples for the Fi assays were coded and tested blindly, the clottable protein and thrombin-time assays were per-

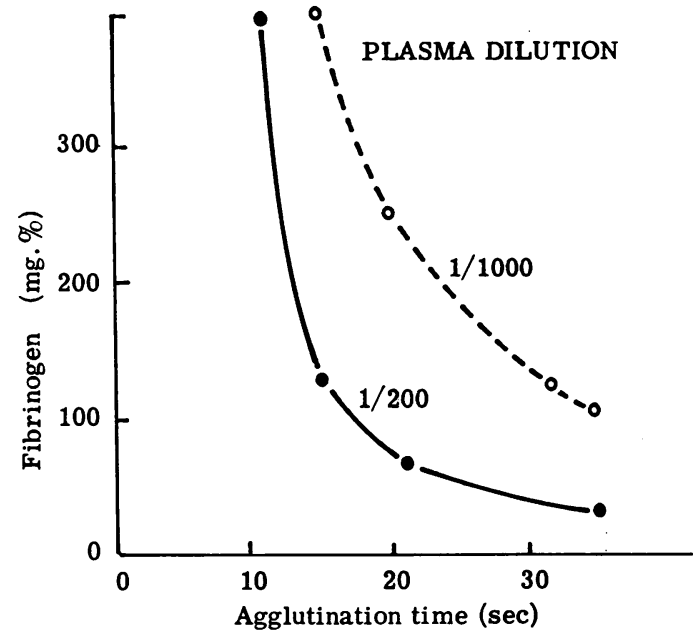

FIG. 1. Standard curves for fibrinogen assay using the modified Fi test. The fibrinogen concentration (ordinate) is plotted against the agglutination time (abscissa) for plasma diluted 1/200 and 1/1,000.

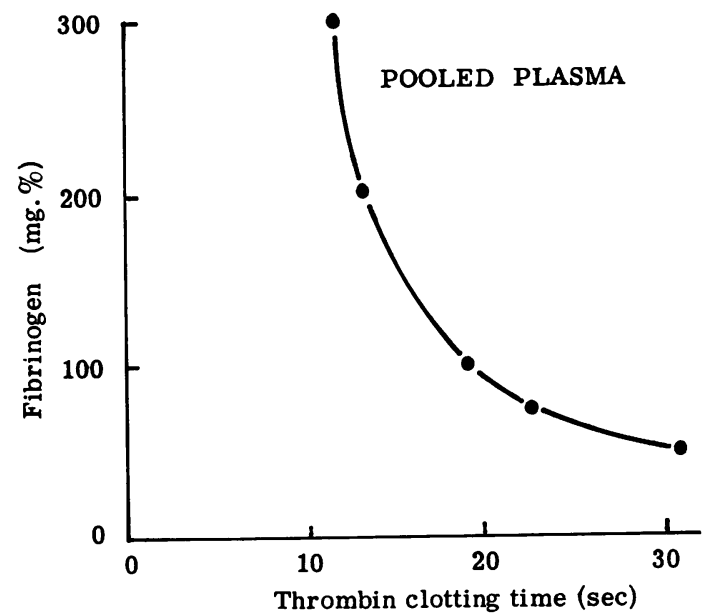

FIG. 2. Standard curve for fibrinogen assay using the thrombin clotting time. The fibrinogen concentration (ordinate) is plotted against the thrombin clotting time (abscissa).

formed, independently, and the results of the three methods compared.

\section{RESULTS}

STANDARD CURVES The standard curves for the $1 / 200$ and $1 / 1,000$ plasma dilutions are shown in Figure 1. The fibrinogen concentration in $\mathrm{mg} \%$ (ordinate) is plotted against agglutination time in 
seconds (abscissa). Quantitation of fibrinogen could best be obtained at agglutination times between 15 and 35 seconds. Thus the standard curve for the dilution 1:200 was suitable for fibrinogen concentrations between 40 and $120 \mathrm{mg} \%$ and the $1: 1,000$ standard curve suitable for concentrations between 100 and $400 \mathrm{mg} \%$.

REPRODUCIBILITY OF ASSAY The assay was performed at least three times on the same plasma sample in 15 patients. The range with reference to the mean value varied from $\pm 50 \%$ for fibrinogen levels of approximately $50 \mathrm{mg} \%$ to less than $\pm 20 \%$ for fibrinogen levels over $300 \mathrm{mg} \%$ (Table I).

TABLE I

REPRODUCIBILITY

\begin{tabular}{ccc} 
Mean & $\begin{array}{l}\text { Number of } \\
\text { Determinations }\end{array}$ & Range \\
\hline 305 & 4 & $260-330$ \\
278 & 5 & $250-300$ \\
267 & 6 & $240-320$ \\
237 & 5 & $205-270$ \\
$224^{1}$ & 5 & $180-260$ \\
205 & 3 & $190-220$ \\
$178^{1}$ & 6 & $120-240$ \\
$160^{1}$ & 3 & $130-190$ \\
$148^{1}$ & 5 & $110-190$ \\
$137^{1}$ & 3 & $125-150$ \\
$88^{1}$ & 4 & $75-100$ \\
$84^{1}$ & 3 & $55-130$ \\
$74^{1}$ & 4 & $55-100$ \\
$55^{1}$ & 5 & $25-75$ \\
$53^{1}$ & 5 & $40-80$
\end{tabular}

'Streptokinase-treated patients.

CORRELATION OF RESULTS OF FI TEST WITH A CLOTTABLE PROTEIN METHOD IN NORMAL SUBJECTS The results of fibrinogen assays performed by the Fi test (abscissa) and clottable protein method (ordinate) are shown in Figure 3. Assays were performed on

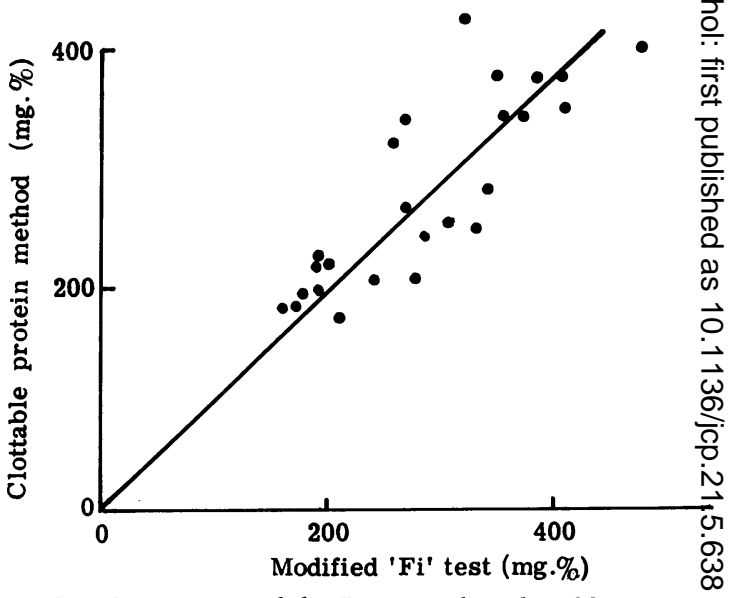

FIG. 3. Comparison of the Fi test with a clottable protein음 method in normal subjects. The results of fibrinogen assays. using the modified Fi test (abscissa) are plotted against(c) the results of a clottable protein method (ordinate). There $\mathbb{D}$ is a significant linear correlation $(r=0.88, \mathrm{P}<0.001) \underset{\mathbb{D}}{(}$ between the results of the two methods.

plasma samples from 25 normal subjects and a $\vec{\varphi}$ highly significant linear correlation $(r=0.88, \infty$ $P<0.001)$ between the two methods was obtained. FIBRINOGEN ESTIMATIONS IN PATIENTS WITH INDUCED FIBRINOLYTIC STATES The results are shown in Figures $4 \mathrm{~A}$ and $4 \mathrm{~B}$. There was a significant corre- $\frac{\mathrm{O}}{\mathrm{D}}$

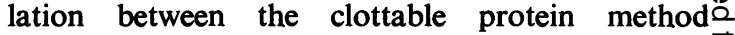
(abscissa) and the Fi test (ordinate) ( (Fig. 4A) $\overrightarrow{\overrightarrow{0}}$ $(r=0.82 ; \quad P<0.001))$ and with the thrombin 3 clotting time method ((ordinate) (Fig. 4B) $(r==$ $0.78 ; \mathrm{P}<001)$ ). Both the Fi test (Fig. 4A) and the thrombin clotting time method (Fig. 4B) gave lowero results than the clottable protein method. However,

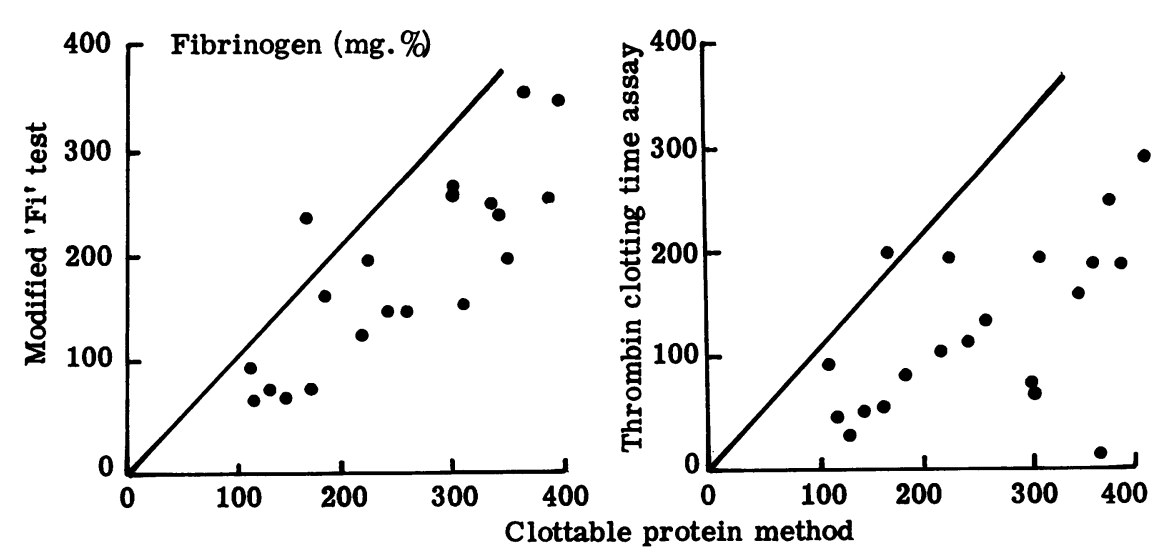

A
B
FIG. 4. Comparison of the Fi test and thrombin clotting time with a clottable protein method in induced fibrinolytic

states. The results of fibrinogen estimations in induced fibrinolytic states using the modified Fi test (ordinate, left) and thrombin clotting time assay (ordinate, right) are compared with a clottable protein assay (abscissae). Both methods yielded lower results than the clottable protein assay but the difference was less marked with results obtained using the Fi test. 


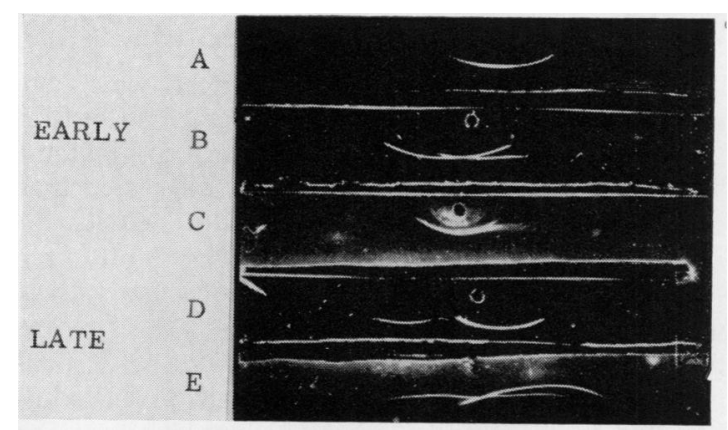

FIG. 5. Immunoelectrophoresis of fibrinogen and fibrinogen and fibrin breakdown products. Fibrinogen is seen as a single precipitin line $(A)$. Early fibrinogen breakdown products appear as two distinct components which separate further after digestion for 24 hours (B). Early fibrin breakdown products are seen as two components, one distinct and one blurred $(C)$. Late fibrin breakdown products appear as two widely separated lines $(D, E)$.

the results obtained with the thrombin clotting time method were lower than those obtained by the Fi test.

IMMUNOELECTROPHORESIS OF BREAKDOWN PRODUCTS Immunoelectrophoresis of fibrinogen and the early and late fibrinogen and fibrin breakdown products is shown in Figure 5. The preparations were reacted with fibrinogen antiserum. Fibrinogen is seen as a single precipitin line, the early fibrinogen breakdown products as two components with similar electrophoretic mobility, the early fibrin breakdown products as a distinct precipitin line and a less distinct component, and the late breakdown products of both fibrinogen and fibrin as two widely separated components.
EFFECT OF FIBRINOGEN AND FIBRIN BREAKDOWN PRODUCTS ON THE FI TEST Early and late fibrinogen and fibrin breakdown products prepared from a solution containing $200 \mathrm{mg} \%$ of fibrinogen were diluted 1/200 and 1/1,000 and tested against the $\mathrm{Fi}$ reagent. Early fibrin breakdown products agglutinated the Fi reagent and produced a standard curve similar to fibrinogen. The other breakdown product preparations failed to induce agglutination within one minute.

Mixtures of fibrinogen and either fibrinogen or fibrin breakdown products were prepared to provide increasing concentrations of breakdown products in $200 \mathrm{mg} \%$ of fibrinogen. In Fig. 6A the fibrinogen concentration estimated from the Fi test (ordinate) is plotted against the concentration of early and late fibrinogen or fibrin breakdown products (abscissa). Addition of early fibrinogen breakdown products decreased the fibrinogen result while addition of early fibrin breakdown products increased this result. In contrast, the late breakdown products of both fibrinogen and fibrin had little effect on the result. The effect of early fibrinogen breakdown products on the Fi test and thrombin time assay is shown in Figure 6B. These early fibrinogen breakdown products interfered with both tests but the fibrinogen level estimated by the thrombin clotting time was considerably lower than that estimated by the Fi test.

\section{DISCUSSION}

The results of these investigations indicate that the Fi test can be modified to quantitate plasma fibrinogen. The assay was sensitive over a wide range of fibrinogen concentrations and its reproduci-

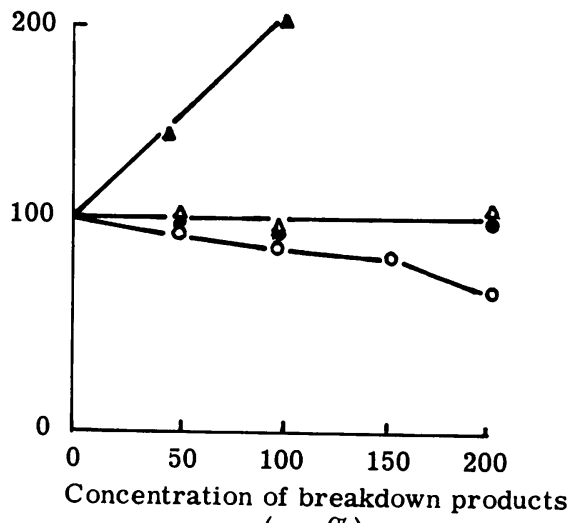

(mg.\%)

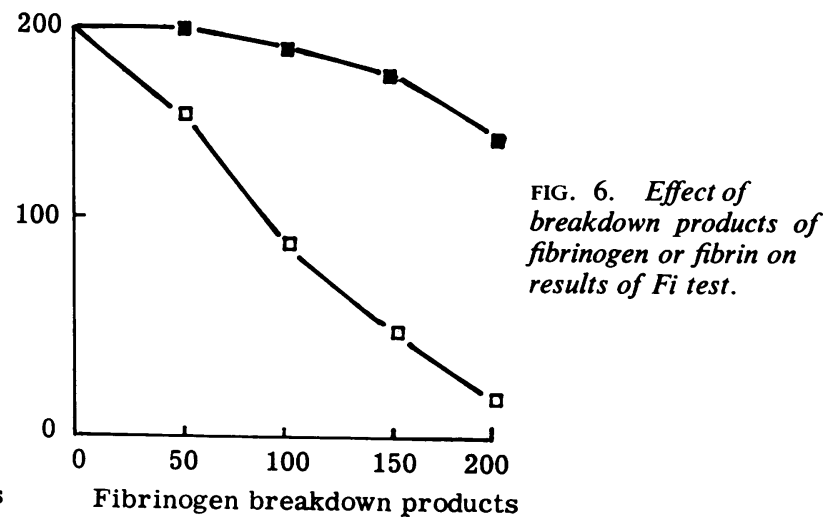

B 
bility, even at very low concentrations, was acceptable for clinical purposes. Both the modified Fi test and thrombin time assay gave falsely low values in patients with induced fibrinolytic states; however, this effect was more marked with the thrombin time assay. Studies in vitro with fibrinogen and fibrin breakdown products suggested that the falsely low values obtained with the Fi test were caused by early fibrinogen breakdown products. The immunoelectrophoretic studies demonstrated that early and late fibrinogen and fibrin breakdown products reacted with fibrinogen antiserum. However, only two of the four types of breakdown products appeared to react with the Fi reagent. The early fibrin breakdown products agglutinated the Fi reagent in a similar manner to fibrinogen, while the early fibrinogen breakdown products did not produce macroscopic agglutination but interfered with fibrinogen-induced agglutination. In contrast, the late products of both fibrinogen and fibrin breakdown neither agglutinated the Fi reagent nor appeared to interfere with fibrinogen-induced agglutination. It is likely that the immunoreactivity with the Fi reagent of fibrinogen and the breakdown products of fibrinogen and fibrin is related to the size and the number of antigenically active sites on the individual particles and that all four types of breakdown products react with the $\mathrm{Fi}$ reagent but that the late products, because of their relatively small size, are unable to agglutinate the Fi reagent.

Immunoassay of serum for fibrinogen and fibrin breakdown products has been used as a method for assessing plasma fibrinolytic activity (Merskey, 을 Kleiner, and Johnson, 1966). Fletcher (1965) $\overrightarrow{\vec{F}}$ combined acrylamide gel electrophoresis with agar? gel diffusion and demonstrated that fibrinogen breakdown produces a complex pattern of high and $\frac{\bar{c}}{\bar{c}}$ low molecular weight derivatives. He suggested that $\vec{\nabla}$ the assessment of plasma fibrinolytic activity by $\varrho$ immunoassay of serum had serious limitations $\%$ because a proportion of high molecular derivatives $\overrightarrow{0}$ was removed during clot formation. The present $\overrightarrow{-}$ findings of changing immunoreactivity with pro- $\vec{\omega}$ gressive digestion of fibrinogen and fibrin complement these observations and further emphasize the limitations of assessing plasma fibrinolytic activity by immunoassay of proteolysis products on in serum.

\section{REFERENCES}

Alkjaersig, N., Fletcher, A. P., and Sherry, S. (1959). J. clin. Invest., $38,1086$.

Blombäck, B., and Blombäck, M. (1956). Ark. Kemi, 10, 415.

Crowle, A. J. (1961). Immunodiffusion, p. 209. Academic Press, New York.

Fletcher, A. P. (1965). Fed. Proc., 24, 822.

Fox, F. J., Jr, Wide, L., Killander, J., and Gemzell, C. (1965), ( Scand. J. clin. Lab. Invest., 17, 341.

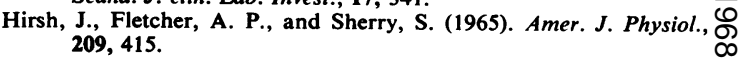

Merskey, C., Kleiner, G. J., and Johnson, A. J. (1966) Blood, 28, Ratnoff, O. D., and Menzie, C. (1951). J. Lab. clin. Med., 37, 316.

Schneider, C. L. (1952). Amer. J. Obstet. Gynec., 64, 141.

Tocantins, L. M., and Kazal, L. A (1964), Blood Coagulation Hemorrhage and Thrombosis, 2nd ed., p. 219. Grüne and Stratton, New York and London.

Vermylen, C., Verstraete, M., and de Vreker, R. (1963). Acta clin. belg., 18, 200

Zucker, M. B., Pert, J. H., and Hilgartner, M. W. (1966). Blood, 28, 524 . 